This is a postprint of the article published in

Current Drug Targets, 2011, 12, 1574-1580

DOI: $10.2174 / 138945011798109446$

PMID: 21561424 (PubMed)

\title{
Controlling Protein Transport by Small Molecules
}

Karl Gademann

University of Basel

Department of Chemistry

St. Johanns-Ring 19

CH-4056 Basel

Switzerland

karl.gademann@unibas.ch

http://www.chemie.unibas.ch/ gademann 


\begin{abstract}
Many proteins are transported from the nucleus to the cytoplasm by the exportin CRM1, which recognizes cargo proteins through a leucine rich nuclear export signal (NES). This nuclear export process can be inhibited by several small molecules, both natural products and fully synthetic compounds. The structural basis for the inhibition of nuclear export by leptomycin (LMB) based on disruption of the protein/protein interaction between CRM1 and cargo proteins is discussed. The chemistry and inhibition of nucleocytoplasmic transport of leptomycin, anguinomycin and derivatives, goniothalamin, JBIR-02, valtrate, dihydrovaltrate, ACA, peumusolide A and several synthetic compounds is presented. Consequences for the design of nuclear export inhibitors is discussed, and the potential of these compounds as anticancer agents is evaluated.
\end{abstract}

\title{
Keywords
}

Nuclear Export - Natural Products - Chemical Biology - Anticancer Compounds - Cell Biology 


\section{Introduction}

Natural products often display the ability to selectively interact with biological targets from all major classes of biopolymers.[1] The successful application of these molecular interactions in living cells and organisms can result in the generation of desired phenotypes (so-called chemical genetics).[2] In contrast to classical genetic methods, the use of chemical interference allows for a spatial, temporal and dynamic control of phenotypes in living systems. [3] In addition, phenotypes can be generated that result from the inhibition of key pathways central to cellular viability. As many small molecule induced interferences are reversible or can be washed out, the resulting phenotypes can be transiently generated and studied. Over the last years, significant progress has been made in the inhibition of enzymes such as kinases, phosphatases and proteases and thus the shutdown of whole biochemical pathways.[4] This highlights the importance of selective chemical interference in biological systems by natural products.

An interesting target for chemical interference is the control over the localization of proteins in living cells. [5-7] By achieving this goal, control over key biochemical pathways (i.e. by controlling the involved transporters) in a complementary manner to the classical enzyme inhibitors might be feasible.[8-10] In addition, by following this strategy, indirect control over non-enzyme biological modulators such as transcription factors of repressors, that are often regulated by nucleocytoplasmic shuttling, can be achieved. [11, 12] The fundamental chemical challenge in achieving this goal consists of the nature of the protein transporters, which usually recognize larger peptide sequences of cargo proteins. For example, the exportin CRM1 recognizes a leucine rich terminal helix,[13-15] the so-called nuclear export signal (NES). [16] Thus for successful interference, small molecules should disrupt these protein/protein interactions and are thus required to target larger areas on a protein surface. Due to the difficulty of this subject, the breakdown of protein/protein complexes by small molecules is currently regarded as one of the general challenges in chemical biology. 
In this review, I will summarize chemical approaches to control protein localization based on the inhibition of the CRM1 exportin by small molecules. The discovery and development of small molecule inhibitors of the protein/protein interaction of CRM1 with the NES of cargo proteins will be discussed and the molecular mode of action highlighted. Potential applications regarding the introduction of novel drugs in the clinic or towards new chemical tools in cell biology will be discussed. It should be pointed out that this review highlights recent developments in the field, and several excellent reviews have been published earlier $[17,18]$. 


\section{Structural Background}

In 2009, two X-ray crystal structures of CRM1 interacting with snuportin 1 (SNUPN) have been published [19-21]. A model of the CRM1-SNUPN complex (Figure 1A) highlights the key interactions for molecular binding. The cargo protein SNUPN (in dark grey) is recognized by the exportin CRM1 (solid) through a nuclear export signal (NES, light grey helix, center). This hydrophobic helical appendage confers low affinity of the cargo protein to the exportin by binding into a hydrophobic grove. In particular, several hydrophobic side chains (Met1, Leu4, Leu8, Phe12, Val12) define the interaction between the NES and CRM1. In addition to this structural information, a seminal report from Kudo and colleagues demonstrated that the natural product leptomycin (LMB) is covalently alkylating the reactive Cys reside (528 in human CRM).[22, 23] This nucleophilic residue is located in the upper end of this groove. Based on these data, we have developed molecular models detailing the atomistic interaction of the covalent binding of LMB to CRM1 (Figure 1B). [24]

Figure 1. A: Model of CRM1 (solid) binding to cargo protein SNUPN (dark grey) via the NES (light grey, central).[19-21] B: Ball and stick model of LMB binding to CRM1 (solid). [24]
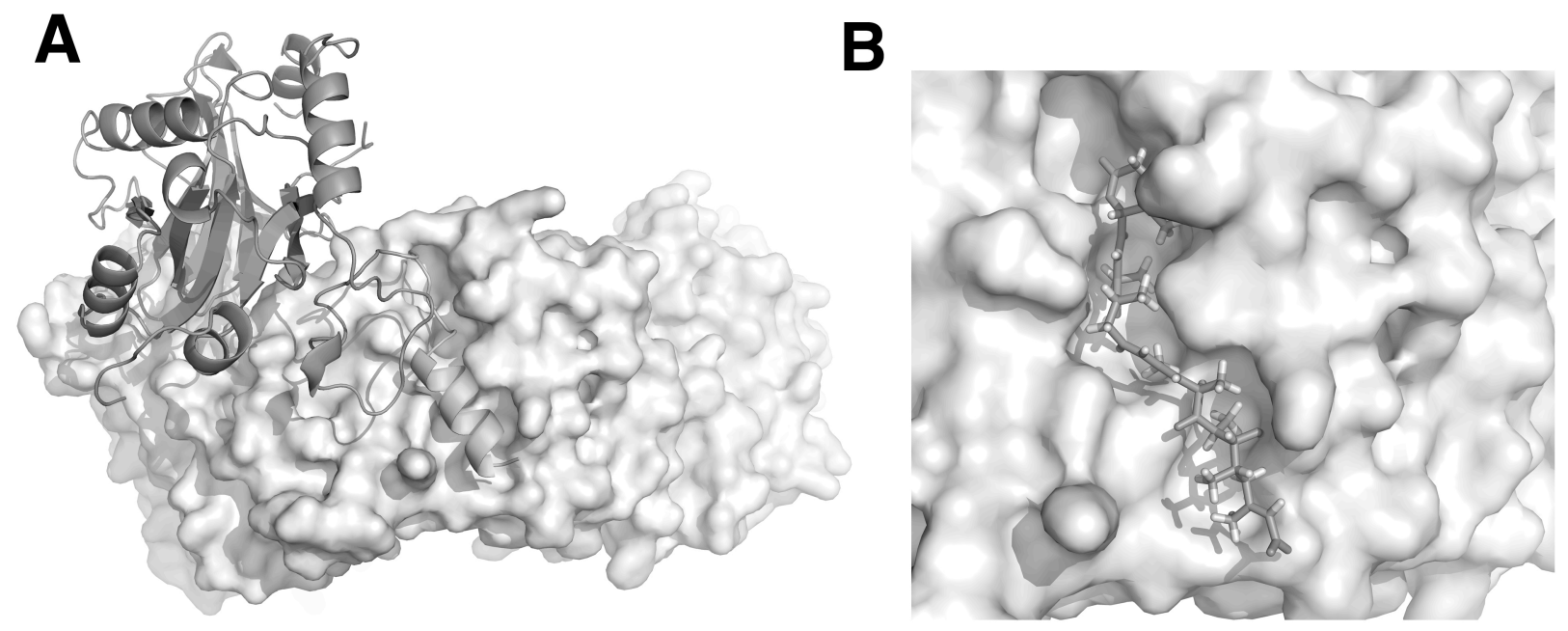
A key feature of the proposed model is that the nuclear export signal of the cargo protein is replaced by LMB in mimicking the hydrophobic nature of the NES and binding to the same groove. As a consequence, the small molecule is thus shutting down this protein/protein interaction as the NES cannot bind anymore.[25, 26] The model of the LMB/CRM1 interaction is characterized by covalent linkage of CRM1 via the nucleophilic Cys residue 528 to the $\alpha, \beta$-unsaturated lactone ring of CRM1. Based on modeling both outcomes of this attack, we proposed that the $R e$ face of the Michael acceptor is attacked, although the calculated energy differences are rather small.[24] Starting from this covalent attachment, the remainder of the LMB molecule was modeled into the grove. It can be postulated that key methyl and ethyl groups in LMB mimic hydrophobic side chains of the NES: The ethyl group at C8 mimics Phe12, and the methyl groups at C14 and C16 mimic Leu8 and Leu4 sidechains. The $\mathrm{C} 10-\mathrm{C} 11$ bond is crucial as by its synclinal arrangement results in a bend shape structure of LMB in the CRM1 binding groove. While LMB is in general very hydrophobic, an electrostatic interaction of the terminal carboxylate with His558 or Lys 514 residues can be postulated to increase binding.

This model helps to explain the salient structural features of leptomycin in displacing the hydrophobic helical appendage NES from the protein cargo.[24] It also details how the cargo CRM1 protein/protein interaction can be disrupted by the covalent anchoring of LMB into the this hydrophobic groove of CRM1. In addition, this model provide structural information on how to modify the leptomycin skeleton to obtain smaller analogs which retain the affinity of disrupting the key protein/protein interaction and therefore inhibiting nuclear export. In the following sections, we will summarize our own research efforts starting from the LMB analogs anguinomycins C (2) and D (3), which have resulted in truncated yet active analog 6 and the target identification of goniothalamin (7). 


\section{Small Molecule Inhibitors of Nuclear Export}

The anguinomycins are potent antitumor agents[27, 28] active in the picomolar range that belong to the leptomycin family of natural products. The anguinomycins $\mathrm{C}$ and $\mathrm{D}$ have been reported to display selectivity against transformed cell lines, while only inducing growth arrest in normal cells.[27] This remarkable selectivity has been attributed to interference with pRB tumor suppressors, as reported in the original isolation publication.[27] In the context of our program on the synthesis of biologically active natural products,[29-36] and intrigued by this remarkable selectivity, we have embarked on a total synthesis of these polyketides for further biological evaluation.[24, 37] In particular, we wanted to examine whether these compounds also constitute inhibitors of the CRM1 mediated nuclear export.

We have synthesized anguinomycins C and D using Jacobsen Cr(III)-catalyzed hetero Diels-Alder reactions, Negishi cross couplings with stereoinversion to obtain the diene part, and Evans syn aldol methodology using the Seebach version of the Evans oxazolidinone. The fragments were merged by using a B-alkyl Suzuki Miyaura coupling, and, after deprotection, the totally synthetic anguinomycins C (2) and D (3) have been obtained. Comparison of spectra confirmed the identify of the synthetic material to the natural product and thus the absolute configuration of the natural product was established as well.[24, 37]

Biological evaluation of the anguinomycins $\mathrm{C}$ and $\mathrm{D}$ by using immunostaining of the Rio2 kinase in HeLa cells demonstrated that anguinomycin C (2) starts to inhibit nucleopcytoplasmic transport at a concentration of $5 \mathrm{nM}$ and a full block is observed at $10 \mathrm{nM}$ concentration. Anguinomycin D (3) leads to full inhibtion at $10 \mathrm{nM}$ concentration. These values demonstrate that anguinomycins $\mathrm{C}$ and D are indeed able to block the CRM1 mediated nuclear export pathway in concentrations which are comparable to LMB itself.[24, 37] 
The aldehyde 4 was evaluated next in order to investigate the role of the lactone moiety. This compound was able to block nuclear export starting at $25 \mathrm{nM}$ with a full shutdown observed at 50 $\mathrm{nM}$. These values confirm that a presence of a lactone is not mandatory for inhibition, and that the cyclic ester moiety in compounds $\mathbf{1 - 3}$ can be substituted by a linear aldehyde group. [24]

Given the structural model developed for LMB binding discussed above (Figure 1B), we wondered whether substitution of the long polyketide tail by a simple hydrocarbon unit would be possible. In particular, we were interested whether the linear propionate part can be substituted by a structurally simpler terpene fragment, for example resulting from citronellal. Such natural product hybrids have been frequently described in the literature, and in the present case, a significant simplification of the synthetic endeavor needed for the preparation of the hybrid would be expected. Indeed, the anguinomycin/terpene hybrid $\mathbf{5}$ is able to block nucleocytoplasmic transport, albeit with loss of activity of one order of magnitude.[24] 
<smiles>CCC(/C=C/C1OC(=O)C=CC1C)=C\C(C)C/C=C/C(C)=C/C(C)C(=O)C(C)C(O)C(C)C/C(C)=C/C(=O)O</smiles>

Leptomycin B (1, LMB)<smiles>[R]/C(=C/C(C)C/C=C/C(C)=C/C(C)C(=O)C(C)C(O)C(C)C/C(C)=C/C)C/C=C/[C@H]1CC=CC(=O)O1</smiles>

Anguinomycin $\mathrm{C}$ (2): $\mathrm{R}=\mathrm{CH}_{3}$

Anguinomycin $\mathrm{D}(\mathbf{3}): \mathrm{R}=\mathrm{C}_{2} \mathrm{H}_{5}$<smiles>C/C=C\C[C@H](O)/C=C/C(=C\C(C)C/C=C/C(C)=C/C(C)C(=O)C(C)C(O)C(C)C/C(C)=C/C)CC</smiles><smiles>CCC(=CC(C)CC=CC[C@@H](C)CCC=C(C)C)CCC1CC=CC(=O)O1</smiles><smiles>CCC(C=C[C@H]1CC=CC(=O)O1)=CC(C)C</smiles>

6<smiles>O=C1C=CCC(/C=C/c2ccccc2)O1</smiles>

Goniothalamin (7)

Figure 2. Inhibitors of nucleocytoplasmic transport.

A key discovery was observed when the truncated analog 6 was evaluated. This compound was obtained as a by-product (from protodepalladation in the fragment coupling) and lacks $13 \mathrm{C}$ atoms of the polyketide chain and five stereogenic centers.[24] Surprisingly, this truncated analog displayed block of nuclear export above $25 \mathrm{nM}$, which represents approximately only a loss of a factor of two when compared to the parent, complex natural product. This result is truly remarkable, 
as usually the bioactivity of natural products is closely related to their structural integrity, and cutting a natural product in two generally leads to a loss of activity. Concerning the question why evolution selected the complete anguinomycin D (3) or leptomycin (1), it should be pointed out that the producing organism was not selected based on its fitness in the CRM1-mediated nuclear export assay, but in much more complex ecological settings. The binding of compound 6 to CRM1 can again be rationalized by molecular modeling, and it can be argued that due to the covalent linkage, the truncated analog irreversibly binds to the exportin thus leading to shutdown of nuclear export.[24]

Based on this key discovery, we wondered whether similar small unsaturated lactones of natural origin would also inhibit CRM1 via s similar mechanism. Goniothalamin (7) is the parent member of a class of similar styryl lactones isolated from various species of plants of the genus Goniothalamus (Annonaceae).[38] A broad manifold of biological activities has been described in many of the roughly 100 reports on this compound, a general cytoxicity against cancer cells, insects, fungi and others have been reported (for recent studies, see refs. [39-43]) In all reports, the exact mechanism of action and the target(s) of goniothalamin remained unclear. We have developed a new eight step synthetic route to goniothalamin (7) and have evaluated this material in the CRM1mediated nuclear export of Rio2 assay.[44] Confirming our initial hypothesis, goniothalamin (7) was indeed demonstrated to be an inhibitor of nucleocytoplasmic transport, and inhibition was observed above $500 \mathrm{nM}$ concentration.[44] As goniothalamin has been reported to display cytotoxivity in breast cancer cells with $\mathrm{IC}_{50}$ value of ca. $1.5 \mu \mathrm{M}$ leading to growth arrest and apoptosis, it can be hypothesized that these effects are based on a block of CRM1-mediated nuclear export at this concentration. This recent study[44] thus enlarged the arsenal of natural products that might be able to interfere and to block the CRM1 mediated nuclear export pathway to other natural products. It might also be tempting to speculate whether compounds endogenous in humans might be able to interfere with this key pathway in human cells. 
<smiles>C/C=C(C)/C=C(\C)C(O)C(C)/C=C(C)/C=C/C/C(C)=C/Cc1[nH]c(OC)cc(=O)c1C</smiles>

JBIR-02 (8)<smiles>CC(=O)OCC1=COC(OC(=O)CC(C)C)C23COC2(COC(=O)CC(C)C)C1C1(CO1)C(OC(=O)CC(C)C)CC3OC(=O)CC(C)C</smiles>

Valtrate (9) Dihydrovaltrate (10)<smiles>C=CC(OC(C)=O)c1ccc(OC(C)=O)cc1</smiles>

ACA (11)<smiles>C=CC(OC(C)=O)c1ccc(OC(C)=O)c(F)c1F</smiles>

13<smiles>C=CC=C1C=CC(=O)C=C1</smiles>

12<smiles>C=C1OC(=O)/C(=C/[13CH2]C)C1O</smiles>

peumusolide $A$ (14)<smiles>CCCCC/C=C\C=C\C(C)(O)CC(=O)O</smiles>

15

Figure 3: Natural products and derivatives targeting nuclear export.

Several other natural products and derivatives have been reported to block nuclear export of cargo proteins. JBIR-02 (8) constitutes a piericidin derivative isolated from a Streptomyces strain in the context of screening for small molecule modulators of arrestin translocation.[45] Arrestins are 
scaffolding proteins that are involved in the internalization and desensitization of G-protein coupled receptors. JBIR-02 inhibited nuclear export of a fluorescent fusion protein of $\beta$-arrestin at a concentration of $20 \mu \mathrm{M}$. Interestingly, the corresponding hydroxyperidine tautomer with an additional $\mathrm{CH}_{3} \mathrm{O}$ group in the 2 position was not active up to $80 \mu \mathrm{M}$ concentration, and displayed cytotoxicity at elevated concentrations. The authors postulated that JBIR-02 (8) operates in a similar manner as LMB in binding to the same hydrophobic grove as discussed earlier.[45]

Valtrate (9), originally isolated by Thies [46] was obtained during a screening of 200 extracts from medicinal plants for nuclear export inhibitors.[47] This compound inhibited Rev export in the fission yeast Schizosaccharomyces pombe at a concentration of $3 \mu \mathrm{g} / \mathrm{mL}$. By using a biotinylated LMB probe, the authors could demonstrate that 9 operates in a mode of action similar to LMB and it was demonstrated that the epoxide can be opened by a protected Cys derivative to give the thiolate adduct, which might be of relevance as a model for CRM1 inhibition. Murakami and coworkers then later developed an interesting synthetic route towards 5,6-dihydrovaltrate (10), which was shown to display only a slightly decreased activity when compared to 9.[48] Nonetheless, the authors noted the limited supply of natural $9(0.006 \%$ isolated yield $)$ as a reason for the total synthesis of this complex iridoid derivative 10.[48]

A similar screen for Rev export inhibitors by the same group resulting in the isolation and characterization of 1'-acetoxychavicol acetate (ACA, 11) from Alpinia galanga. [49] This compound was shown to operate in a similar manner as LMB and was active at $4.7 \mu \mathrm{M}$ concentrationin the fission yeast assay. It demonstrated by the synthesis of analogs that both Ac groups are necessary as is the absolute configuration.[49] A follow-up study proposed that the quinone methide intermediate $\mathbf{1 2}$ would be the biologically active compound, and prepared several compounds allowing to probe the different rates of Ac hydrolysis and elimination. [50] These efforts led to the identifaction of the difluoroanalog 13 , which showed better activity, both in the fission yeast assay $(1.4 \mu \mathrm{M})$ and in the immunostaining assay in HeLa cells (130 nM).[50] 
Peumusolide A (14) was obtained as a NES non-antagonistic inhibitor from the South American medicinal plant Peumus boldus.[51] This compound $\mathbf{1 4}$ has been shown to inhibit the nuclear export of the MAPK/ERK kinase at low micromolar values. The authors suggest that the mode of action is not related to the nuclear export signal (NES), as the compound was found to retain activity when cells were pretreated with a biotinylated probe of LMB. The exact mode of action of this compound needs to be investigated further.[51]

Another NES non-antagonistic inhibitor, the fatty acid derivative 15, was reported by Murakami and co-workers.[52] Synthetic studies aimed at the investigation of structure/activity relationships demonstrated that either truncated, saturated, or small analogs were less active supporting the notion that a cooperation of the carboxylate, the $\mathrm{OH}$ group and the diene in exact distance is required for biological activity.

In addition to these natural products and derivatives, several synthetic compounds interfering with nuclear export have been identified. A chemical genetic screen directed towards the identification of inhibitors of the FOXO1a nuclear export yielded several interesting compounds.[53] From 18000 compounds screened, 42 compounds were identified as export inhibitors. In order to differentiate between general nuclear export inhibitors and more specific inhibitors targeting the PI3K/Akt/FOXO1a signaling pathway, these hits were evaluated in the classical Rev export inhibition assay. Among these compounds, 19 Rev export inhibitors were obtained that were shown to interact with CRM1 mediated nuclear export. A survey of these 19 compounds established that eight compounds contained $\alpha, \beta$-unsaturated ketones such as $\mathbf{1 6}$ or maleimides such as $\mathbf{1 7}$, three contained electrophilic $\mathrm{C}$ atoms with good leaving groups (exemplified by 18). Several alkynes such as 19 were obtained as well as other compounds that do not reveal reactive groups at first sight. A closer investigation of their mode of action would be warranted, although contaminations with reactive compounds could also be plausible.[53] 
<smiles>O=C(/C=C/c1cccc([N+](=O)[O-])c1)c1ccccc1</smiles>

16<smiles>CC(C)(C)c1ccc(OC(=O)NC(=O)CCBr)cc1</smiles>

18<smiles>CCOC(=O)/C=C\n1ncnc1-c1cc(Cl)ccc1N</smiles>

20<smiles>CCOC(=O)/C=C\n1nnc(-c2ccccc2Cl)n1</smiles>

22<smiles>CC1=CC(=O)N(CCc2c[nH]c3ccccc23)C1=O</smiles>

17<smiles>CC(C)(O)C#CC(=O)c1cccc2ccccc12</smiles>

19<smiles>CCOC(=O)/C=C\n1cnc(-c2cc(Cl)ccc2N)n1</smiles>

21<smiles>O=C(/C=C\C(=O)Nc1cccc(Cl)c1)Nc1ccc(Cl)cc1</smiles>

23

Figure 4. Synthetic inhibitors of nuclear export.

Vandamme and coworkers reported in 2002 the triazole $\mathbf{2 0}$ as a low molecular weight inhibitor blocking the CRM1 mediated nuclear export.[54] In a subsequent study, the same group showed that the originally reported structure was erroneous, and that instead the 3-substituted triazole 21 was the active compound.[55] A structure activity study revealed key points for activity, and the presence of the $\alpha, \beta$-unsaturated ester was found necessary, which is in line with earlier studies on covalent inhibitors. Based on these investigations, tetrazole 22 was identified as most potent compound evaluated.[55] A similar set of $\alpha, \beta$-unsaturated amides was identified by a Novartis group in 2009.[56] A sophisticated high content screen for inhibitors of HDAC nuclear export of $>$ 100000 compounds and 1 billion cells resulted in a proposed hit structure. Closer investigation of 
the hit compound revealed that an impurity caused the positive signal, and it was shown that $\alpha, \beta$ unsaturated diamide $\mathbf{2 3}$ was the active compound. This compound resulted in a $2.2 \mathrm{nM}$ concentration for successful inhibition of HDAC5 nuclear export.

\section{Conclusion}

The many disclosures of both natural products and fully synthetic compounds used as nuclear export inhibitors over the last couple of years is a testimony to their power in controlling a key pathway in eukaryotic cells. In addition, their use for chemical interference, resulting in phenotypes that are difficult to obtain by traditional genetics, can be highlighted. The potential of these compounds to treat diseases such as cancer will certainly be evaluated in the future.

\section{Acknowledgement}

K.G. is a European Young Investigator (EURYI). I thank my co-workers in the nuclear export project, Dr. Simone Bonazzi and Mr. Jean-Yves Wach for their intellectual and experimental contributions and my collaborators, Prof. Dr. Ulrike Kutay, Dr. Stephan Güttinger, Dr. Ivo Zemp (all ETH Zürich) and Dr. Oliv Eidam (UC San Francisco) for the great collaboration. I gratefully acknowledge the SNF for support of this work (PE002-117136/1, 200021-115918/1, 20020130475/1). 


\section{References}

[1] Cragg GM, Grothaus PG, Newman DJ. Impact of Natural Products on Developing New Anti-Cancer Agents. Chem Rev. 2009 Jul;109(7):3012-43.

[2] Schreiber SL. Chemical genetics resulting from a passion for synthetic organic chemistry. Bioorgan Med Chem. 1998 Aug;6(8):1127-52.

[3] Hubel K, Lessmann T, Waldmann H. Chemical biology - identification of small molecule modulators of cellular activity by natural product inspired synthesis. Chem Soc Rev. 2008;37(7):1361-74.

[4] Bialy L, Waldmann H. Inhibitors of protein tyrosine phosphatases: Next-generation drugs? Angew Chem Int Ed. 2005;44(25):3814-39.

[5] Görlich D, Mattaj IW. Protein kinesis - Nucleocytoplasmic transport. Science. $1996 ; 271(5255): 1513-8$

[6] Rothman JE. Mechanism of Intracellular Protein Transport. Nature. 1994;372(6501):55-63.

[7] Görlich D, Kutay U. Transport between the cell nucleus and the cytoplasm. Ann Rev Cell Develop Biol. 1999;15:607-60.

[8] Ohno M, Fornerod M, Mattaj IW. Nucleocytoplasmic transport: The last 200 nanometers. Cell. 1998;92(3):327-36.

[9] Mattaj IW, Englmeier L. Nucleocytoplasmic transport: The soluble phase. Ann Rev Biochem. 1998;67:265-306.

[10] Nigg EA. Nucleocytoplasmic transport: Signals, mechanisms and regulation. Nature. 1997;386(6627):779-87.

[11] Mansfeld J, Güttinger S, Hawryluk-Gara LA, Pante N, Mall M, Galy V, et al. The conserved transmembrane nucleoporin NDC1 is required for nuclear pore complex assembly in vertebrate cells. Mol Cell. 2006 Apr 7;22(1):93-103. 
[12] Güttinger S, Muhlhausser P, Koller-Eichhorn R, Brennecke J, Kutay U. Transportin2 functions as importin and mediates nuclear import of HuR. P Natl Acad Sci USA. 2004 Mar 2;101(9):2918-23.

[13] OssarehNazari B, Bachelerie F, Dargemont C. Evidence for a role of CRM1 in signalmediated nuclear protein export. Science. 1997;278(5335):141-4.

[14] Fukuda M, Asano S, Nakamura T, Adachi M, Yoshida M, Yanagida M, et al. CRM1 is responsible for intracellular transport mediated by the nuclear export signal. Nature. 1997;390(6657):308-11.

[15] Fornerod M, Ohno M, Yoshida M, Mattaj IW. CRM1 is an export receptor for leucine-rich nuclear export signals. Cell. 1997;90(6):1051-60.

[16] Kutay U, Güttinger S. Leucine-rich nuclear-export signals: born to be weak. Trends Cell Biol. 2005 Mar;15(3):121-4.

[17] Kalesse M, Christmann M. The chemistry and biology of the leptomycin family. SynthesisStuttgart. 2002 Jun(8):981-1003.

[18] Yashiroda Y, Yoshida M. Nucleo-cytoplasmic transport of proteins as a target for therapeutic drugs. Curr Med Chem. 2003 May;10(9):741-8.

[19] Dong XH, Biswas A, Suel KE, Jackson LK, Martinez R, Gu HM, et al. Structural basis for leucine-rich nuclear export signal recognition by CRM1. Nature. 2009 Apr;458(7242):1136U71.

[20] Dong XH, Biswas A, Chook YM. Structural basis for assembly and disassembly of the CRM1 nuclear export complex. Nat Struct Mol Biol. 2009 May;16(5):558-60.

[21] Monecke T, Guttler T, Neumann P, Dickmanns A, Görlich D, Ficner R. Crystal Structure of the Nuclear Export Receptor CRM1 in Complex with Snurportin1 and RanGTP. Science. 2009 May;324(5930):1087-91. 
[22] Kudo N, Matsumori N, Taoka H, Fujiwara D, Schreiner EP, Wolff B, et al. Leptomycin B inactivates CRM1/exportin 1 by covalent modification at a cysteine residue in the central conserved region. P Natl Acad Sci USA. 1999;96(16):9112-7.

[23] Kudo N, Wolff B, Sekimoto T, Schreiner EP, Yoneda Y, Yanagida M, et al. Leptomycin B inhibition of signal-mediated nuclear export by direct binding to CRM1. Exper Cell Res. 1998;242(2):540-7.

[24] Bonazzi S, Eidam O, Güttinger S, Wach JY, Zemp I, Kutay U, Gademann K. Anguinomycins and Derivatives: Total Syntheses, Modeling, and Biological Evaluation of the Inhibition of Nucleocytoplasmic Transport. J Am Chem Soc. 2010 Feb 3;132(4):143242.

[25] Wolff B, Sanglier JJ, Wang Y. Leptomycin B is an inhibitor of nuclear export: Inhibition of nucleo-cytoplasmic translocation of the human immunodeficiency virus type 1 (HIV-1) Rev protein and Rev-dependent mRNA. Chem Biol. 1997 Feb;4(2):139-47.

[26] Nishi K, Yoshida M, Fujiwara D, Nishikawa M, Horinouchi S, Beppu T. Leptomycin B targets a regulatory cascade of CRM1, a fission yeast nuclear protein, involved in control of higher-order chromosome structure and gene-expression. J Biol Chem 1994 Mar;269(9):6320-4.

[27] Hayakawa Y, Sohda K, Shinya K, Hidaka T, Seto H. Anguinomycin-C and Anguinomycin D, New Antitumor Antibiotics with selective Cytotoxicity Against Transformed Cells. J Antibiot. 1995;48(9):954-61.

[28] Hayakawa Y, Adachi K, Komeshima N. New Antitumor Antibiotics, Anguinomycin-A and Anguinomycin-B. J Antibiot. 1987;40(9):1349-52.

[29] Bonazzi S, Binaghi M, Fellay C, Wach JY, Gademann K. Synthetic Studies on the Sporolides: Exploration of the Enediyne Route. Synthesis-Stuttgart. 2010(4):631-42. 
[30] Bonazzi S, Barbaras D, Patiny L, Scopelliti R, Schneider P, Cole ST, et al. Antimalarial and antitubercular nostocarboline and eudistomin derivatives: Synthesis, in vitro and in vivo biological evaluation. Bioorgan Med Chem. 2010;18(4):1464-76.

[31] Wach JY, Gademann K. Enantioselective Synthesis of the Sporolide Quinone Acid Fragment. Synlett. 2009(17):2849-51.

[32] Jessen HJ, Barbaras D, Hamburger M, Gademann K. Total Synthesis and Neuritotrophic Activity of Farinosone C and Derivatives. Org Lett. 2009;11(15):3446-9.

[33] Gademann K, Portmann C. Secondary metabolites from cyanobacteria: Complex structures and powerful bioactivities. Current Organic Chemistry. 2008;12(4):326-41.

[34] Gademann K, Bethuel Y, Locher HH, Hubschwerlen C. Biomimetic total synthesis and antimicrobial evaluation of anachelin H. J Org Chem. 2007;72:8361-70.

[35] Gademann K, Bethuel Y. Total synthesis of anachelin H. Org Lett. 2004;6(25):4707-10.

[36] Gademann K, Bethuel Y. A biomimetic route to the peptide alkaloid anachelin. Angew Chem Int Ed. 2004;43(25):3327-9.

[37] Bonazzi S, Güttinger S, Zemp I, Kutay U, Gademann K. Total synthesis, configuration, and biological evaluation of anguinomycin C. Angew Chem Int Ed. 2007;46(45):8707-10.

[38] Jewers K, Blunden G, Wetchapi.S, Dougan J, Manchand.Ah, Davis JB, et al. Goniothalamin and its Distribution in 4 Goniothalamus species. Phytochem. 1972;11(6):2025-\&.

[39] Inayat-Hussain SH, Chan KM, Rajab NF, Din LB, Chow SC, Kizilors A, et al. Goniothalamin-induced oxidative stress, DNA damage and apoptosis via caspase-2 independent and Bcl-2 independent pathways in Jurkat T-cells. Toxicology Letters. 2010;193(1):108-14.

[40] Martins CVB, de Resende MA, da Silva DL, Magalhaes TFF, Modolo LV, Pilli RA, et al. In vitro studies of anticandidal activity of goniothalamin enantiomers. J Appl Microbiol. 2009;107(4):1279-86. 
[41] Senthil-Nathan S, Choi MY, Paik CH, Kalaivani K. The toxicity and physiological effect of goniothalamin, a styryl-pyrone, on the generalist herbivore, Spodoptera exigua Hubner. Chemosphere. 2008;72(9):1393-400.

[42] Martins CVB, de Resende MA, Magalhaes TFF, Lima BHS, Watanabe GA, Ruiz A, et al. Antifungal activity of goniothalamin enantiomers. Lett Drug Des Discov. 2008;5(1):74-8.

[43] de Fatima A, Zambuzzi WF, Modolo LV, Tarsitano CAB, Gadelha FR, Hyslop S, et al. Cytotoxicity of goniothalamin enantiomers in renal cancer cells: Involvement of nitric oxide, apoptosis and autophagy. Chemico-Biological Interactions. 2008;176(2-3):143-50.

[44] Wach JY, Güttinger S, Kutay U, Gademann K. The cytotoxic styryl lactone goniothalamin is an inhibitor of nucleocytoplasmic transport. Bioorg Med Chem Lett. 2010 May 1;20(9):2843-6.

[45] Ueda JY, Togashi T, Matukura S, Nagai A, Nakashima T, Komaki H, et al. A Novel nuclear export inhibitor JBIR-02, a new piericidin discovered from streptomyces sp ML55. J Antibiot. 2007;60:459-62.

[46] Thies PW. Constitution of Valepotriates. Report of Active Agents of Valerian. Tetrahedron. 1968;24(1):313-\&.

[47] Murakami N, Ye Y, Kawanishi M, Aoki S, Kudo N, Yoshida M, et al. New Rev-transport inhibitor with anti-HIV activity from Valerianae Radix. Bioorg Med Chem Lett. 2002 Oct;12(20):2807-10.

[48] Tamura S, Shimizu N, Fujiwara K, Kaneko M, Kimura T, Murakami N. Bioisostere of valtrate, anti-HIV principle by inhibition for nuclear export of Rev. Bioorg Med Chem Lett. 2010 Apr;20(7):2159-62.

[49] Tamura S, Shiomi A, Kaneko M, Ye Y, Yoshida M, Yoshikawa M, et al. New Rev-export inhibitor from Alpinia galanga and structure-activity relationship. Bioorg Med Chem Lett. 2009 May;19(9):2555-7. 
[50] Tamura S, Shiomi A, Kimura T, Murakami N. Halogenated analogs of 1 '-acetoxychavicol acetate, Rev-export inhibitor from Alpinia galanga, designed from mechanism of action. Bioorg Med Chem Lett. 2010 Apr;20(7):2082-5.

[51] Tamura S, Hattori Y, Kaneko M, Shimizu N, Tanimura S, Kohno M, et al. Peumusolide A, unprecedented NES non-antagonistic inhibitor for nuclear export of MEK. Tetrahedron Lett. 2010;51(13):1678-81.

[52] Tamura S, Kaneko M, Shiomi A, Yang GM, Yamaura T, Murakami N. Unprecedented NES non-antagonistic inhibitor for nuclear export of Rev from Sida cordifolia. Bioorg Med Chem Lett. 2010 Mar;20(6):1837-9.

[53] Kau TR, Schroeder F, Ramaswamy S, Wojciechowski CL, Zhao JJ, Roberts TM, et al. A chemical genetic screen identifies inhibitors of regulated nuclear export of a Forkhead transcription factor in PTEN-deficient tumor cells. Cancer Cell. 2003;4(6):463-76.

[54] Daelemans D, Afonina E, Nilsson J, Werner G, Kjems J, De Clercq E, et al. A synthetic HIV-1 Rev inhibitor interfering with the CRM1-mediated nuclear export. P Natl Acad Sci USA. 2002;99(22):14440-5.

[55] Van Neck T, Pannecouque C, Vanstreels E, Stevens M, Dehaen W, Daelemans D. Inhibition of the CRM1-mediated nucleocytoplasmic transport by N-azolylacrylates: Structure-activity relationship and mechanism of action. Bioorgan Med Chem. 2008 Nov;16(21):9487-97.

[56] Monovich L, Koch KA, Burgis R, Osimboni E, Mann T, Wall D, et al. Suppression of HDAC nuclear export and cardiomyocyte hypertrophy by novel irreversible inhibitors of CRM1. Biochimica Et Biophysica Acta-Gene Regulatory Mechanisms. 2009 May;1789(5):422-31. 